\title{
BMJ Open Patient and carer experience of hospital- based rehabilitation from intensive care to hospital discharge: mixed methods process evaluation of the RECOVER randomised clinical trial
}

Pam Ramsay, ${ }_{1}^{1}$ Guro Huby, ${ }^{2}$ Judith Merriweather, ${ }^{1}$ Lisa Salisbury, ${ }^{3}$ Janice Rattray, ${ }^{4}$ David Griffith, ${ }^{1}$ Timothy Walsh, ${ }^{1}$ on behalf of the RECOVER collaborators

To cite: Ramsay P, Huby G, Merriweather J, et al. Patient and carer experience of hospital-based rehabilitation from intensive care to hospital discharge: mixed methods process evaluation of the RECOVER randomised clinical trial. BMJ Open 2016;6:e12041.

doi:10.1136/bmjopen-2016012041

- Prepublication history and additional material is available. To view please visit the journal (http://dx.doi.org/ 10.1136/bmjopen-2016012041)

Received 31 March 2016 Revised 23 May 2016 Accepted 16 June 2016 CrossMark

${ }^{1}$ Department of Anaesthesia and Critical Care, Royal Infirmary of Edinburgh, Edinburgh, UK

${ }^{2}$ Faculty of Health and Social Studies, University College Østfold, Halden, Norway ${ }^{3}$ Department of Nursing, University of Edinburgh, Edinburgh, UK

${ }^{4}$ School of Nursing and Midwifery, University of Dundee, Dundee, UK

Correspondence to Dr Pam Ramsay; pam.ramsay@ed.ac.uk

\section{ABSTRACT}

Objectives: To explore and compare patient/carer experiences of rehabilitation in the intervention and usual care arms of the RECOVER trial

(ISRCTN09412438); a randomised controlled trial of a complex intervention of post-intensive care unit (ICU) acute hospital-based rehabilitation following critical illness.

Design: Mixed methods process evaluation including comparison of patients' and carers' experience of usual care versus the complex intervention. We integrated and compared quantitative data from a patient experience questionnaire (PEQ) with qualitative data from focus groups with patients and carers.

Setting: Two university-affiliated hospitals in Scotland. Participants: 240 patients discharged from ICU who required $\geq 48$ hours of mechanical ventilation were randomised into the trial (120 per trial arm). Exclusion criteria comprised: primary neurologic diagnosis, palliative care, current/planned home ventilation and age $<18$ years. 182 patients completed the PEQ at 3 months postrandomisation. 22 participants (14 patients and 8 carers) took part in focus groups ( 2 per trial group) at $>3$ months postrandomisation.

Interventions: A complex intervention of post-ICU acute hospital rehabilitation, comprising enhanced physiotherapy, nutritional care and information provision, case-managed by dedicated rehabilitation assistants (RAs) working within existing ward-based clinical teams, delivered between ICU discharge and hospital discharge. Comparator was usual care.

Outcome measures: A novel PEQ capturing patientreported aspects of quality care.

Results: The PEQ revealed statistically significant between-group differences across 4 key intervention components: physiotherapy $(p=0.039)$, nutritional care $(p=0.038)$, case management $(p=0.045)$ and information provision $(p<0.001)$, suggesting greater patient satisfaction in the intervention group. Focus group data strongly supported and helped explain these findings. Specifically, case management by dedicated RAs facilitated greater access to physiotherapy, nutritional care and information that cut

\section{Strengths and limitations of this study}

- Our trial is among the very few critical care complex interventional trials to incorporate the Medical Research Council's (MRC) recommendations for outcomes and process evaluation into its evaluation strategy.

- Our trial is among the very few such trials to critically explore patient experience, using a novel patient experience questionnaire and qualitative methods.

- Exploring patient experience helped identify the perceived value of each interventional component and the means to individualise post-ICU rehabilitation in accordance with National Institute for Health and Care Excellence guidance.

- The patient experience questionnaire has yet to be psychometrically validated.

- Sample size was small in our comparative focus group interviews.

across disciplinary boundaries and staffing constraints. Patients highly valued its individualisation according to their needs, abilities and preferences.

Conclusions: Case management by dedicated RAs improves patients' experiences of post-ICU hospital-based rehabilitation and increases perceived quality of care. Trial registration number: ISRCTN09412438.

\section{INTRODUCTION}

Intensive care unit (ICU) survivors commonly experience physical, psychological and cognitive impairment, recently termed the postintensive care syndrome'. ${ }^{\prime}$ National Institute for Health and Care Excellence recommends regular assessment and individualised rehabilitation for these patients, ${ }^{2}$ but optimum rehabilitation components and service delivery models are uncertain. Several 
trials have evaluated rehabilitation interventions conducted or initiated during the ICU stay, ${ }^{3-7}$ the acute hospital stay ${ }^{8}$ and after hospital discharge. ${ }^{9-12}$ Systematic reviews suggest that early ICU-based interventions may be effective, ${ }^{13-16}$ but interventions starting post-ICU discharge, including the RECOVER study, ${ }^{17}$ have failed to demonstrate clinical efficacy using recommended quantitative outcome-based approaches. ${ }^{18}$

Recognising the limitations of outcome evaluations of complex interventions alone, the Medical Research Council (MRC) recommends, in addition, the process evaluation of complex interventions. ${ }^{19}$ This is intended to describe the fidelity and quality of implementation, clarify causal mechanisms and identify contextual influences that may influence outcomes. ${ }^{19}$ Specific recommendations from subsequent guidance include: exploring patients' experiences of the intervention and the use of qualitative approaches to explain quantitative findings. ${ }^{20}$ With the exception of a single study, ${ }^{21}$ however, previous trials of rehabilitation interventions in this patient group have failed to describe patient experience of the intervention, therefore preventing detailed understanding of potentially beneficial components and/or treatments.

We recently reported the quantitative outcomes of a randomised controlled trial (RCT) of increased hospital-based physical rehabilitation and information provision following
ICU discharge (RECOVER trial; ISRCTN09412438 ${ }^{17}$ ). The intervention involved a dedicated rehabilitation assistant (RA) working within existing ward-based clinical teams to increase the frequency and intensity of physiotherapy and nutritional care, together with individualised critical illnessrelated information provision, from ICU to hospital discharge. The comparator was current usual care (figure 1, online supplementary files for a summary of trial design and content). We found no between-group differences across quantitative measures of physical function (Rivermead Mobility Index, ${ }^{22}$ hand-grip strength, the timed-up-and-go test, ${ }^{23}$ health-related quality of life (HRQoL; SF-12 ${ }^{24}$ ), self-reported symptoms (fatigue, pain, appetite, joint stiffness, breathlessness using visual analogue scales (VAS) ) or rates of anxiety, depression and posttraumatic stress using the Hospital Anxiety and Depression Scale $^{25}$ and Davidson's Trauma Scale, respectively, ${ }^{26}$ at 3,6 or 12 months postrandomisation.

However, a patient experience questionnaire (PEQ) administered at 3 months post-randomisation indicated that patient satisfaction scores were higher among the intervention group across four key intervention components. In this article, we report the findings of a preplanned, mixed methods process evaluation, comprising the triangulation of PEQ data with qualitative data from comparative focus group interviews with patients/carers. Our aim was to better understand and compare patients'

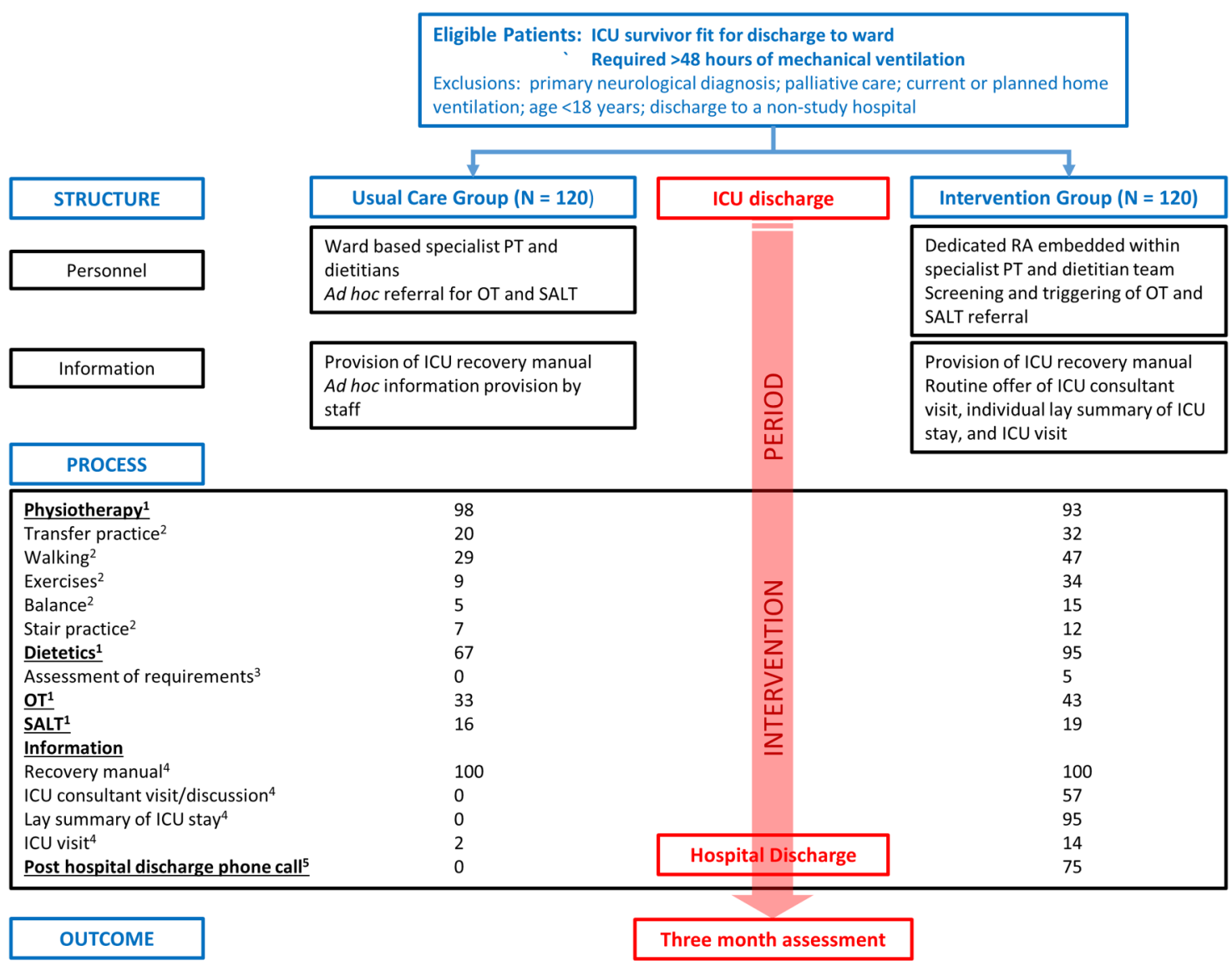

Figure 1 Trial design and content. 
experiences of rehabilitation in the trial, and specifically to explore effects on perceived quality of care that were unlikely to be captured with traditional quantitative outcome measures.

\section{METHODS}

We conducted a mixed methods analysis of populationlevel quantitative data from the PEQ ( $\mathrm{n}=182$ respondents) and qualitative analysis of comparative focus groups ( $\mathrm{n}=22$ participants), as part of a preplanned process evaluation of the trial.

\section{Trial overview}

RECOVER was a parallel group, complex intervention RCT with blinded outcome assessment, undertaken in two university-affiliated hospitals in Edinburgh, Scotland. ${ }^{17}$ The intervention development, trial protocol and quantitative trial outcomes have been published previously. ${ }^{27-30}$ A summary of trial design, content and key differences in rehabilitation treatment are shown in figure 1.

In accordance with MRC guidance on the process evaluation of complex interventions, ${ }^{20}$ we conducted focus groups with patient participants and family members from both trial arms to explore and compare experiences of rehabilitation. We planned an a priori mixed methods process evaluation of the intervention, by integrating the quantitative PEQ data with the qualitative focus group data, in order to maximise understanding of the individual effects of the intervention's key components.

\section{Patient experience questionnaire}

The PEQ was designed based on pretrial qualitative research (Doctoral thesis) among survivors of prolonged mechanical ventilation $(n=20)$, which identified nine domains of post-ICU acute hospital care and rehabilitation that concerned participants most. ${ }^{31}$ Based on advice from an expert in questionnaire development, these were incorporated within a VAS including anchor points (excellent (0) to poor (20)) and anchor quotes derived from the data ${ }^{29}$ to help patients report their experiences (figure 2, online supplementary files for the PEQ). We explored the face and content validity of the questionnaire by asking a small number of recovering patients to describe the extent to which the PEQ reflected their experiences of ward care. Developing the PEQ on the basis of patients' accounts was intended to maximise the questionnaire's sensitivity to issues that patients previously reported as important markers of quality care. $^{32}$ Questionnaires were completed at 3 months postrandomisation, at the time of primary outcome assessment, with research staff blinded from group allocation.

Scores for each question were compared between the usual care and intervention groups using Mann-Whitney

\begin{tabular}{|c|c|c|c|c|c|c|c|}
\hline SATISFACTION DOMAIN & ANCHOR QUOTE & & & & & & ANCHOR QUOTE \\
\hline \multirow{2}{*}{$\begin{array}{l}\text { Transfer from ICU to the } \\
\text { ward }\end{array}$} & \multirow{2}{*}{$\begin{array}{l}\text { "No one told me what } \\
\text { was happening or what } \\
\text { the wards would be like". }\end{array}$} & & & & & & \multirow{2}{*}{$\begin{array}{l}\text { "The ICU staff prepared me } \\
\text { well for going to the ward." }\end{array}$} \\
\hline & & Poor & OK & Good & $\begin{array}{l}\text { Very } \\
\text { good }\end{array}$ & Excellent & \\
\hline \multirow{2}{*}{$\begin{array}{l}\text { Ward Staff's understanding } \\
\text { of your time in intensive } \\
\text { care }\end{array}$} & \multirow{2}{*}{$\begin{array}{l}\text { "No one had a clue about } \\
\text { what had happened to } \\
\text { me." }\end{array}$} & & & & & & \multirow{2}{*}{$\begin{array}{l}\text { "They really understood and } \\
\text { cared about what I'd been } \\
\text { through." }\end{array}$} \\
\hline & & Poor & OK & Good & $\begin{array}{l}\text { Very } \\
\text { good }\end{array}$ & Excellent & \\
\hline \multirow{2}{*}{$\begin{array}{l}\text { Exercises to get you } \\
\text { moving/back on your feet }\end{array}$} & \multirow{2}{*}{$\begin{array}{l}\text { "I had little or no help, } \\
\text { support or advice and my } \\
\text { recovery suffered as a } \\
\text { result." }\end{array}$} & & & & & & \multirow{2}{*}{$\begin{array}{l}\text { "I had all the help, support and } \\
\text { advice I needed to get me } \\
\text { moving/back on my feet." }\end{array}$} \\
\hline & & Poor & OK & Good & $\begin{array}{l}\text { Very } \\
\text { good }\end{array}$ & Excellent & \\
\hline \multirow{2}{*}{$\begin{array}{l}\text { Help, support and advice } \\
\text { with being independent }\end{array}$} & \multirow{2}{*}{$\begin{array}{l}\text { "I had little or no help, } \\
\text { support or advice and I } \\
\text { really struggled to get my } \\
\text { independence back." }\end{array}$} & & & & & & \multirow{2}{*}{$\begin{array}{l}\text { "I had all the help, support } \\
\text { and advice I needed to get } \\
\text { my independence back." }\end{array}$} \\
\hline & & Poor & OK & Good & $\begin{array}{l}\text { Very } \\
\text { good }\end{array}$ & Excellent & \\
\hline \multirow{2}{*}{$\begin{array}{l}\text { Help with eating and } \\
\text { nutrition }\end{array}$} & \multirow{2}{*}{$\begin{array}{l}\text { "No one seemed to } \\
\text { notice or care if I was } \\
\text { able to eat ok." }\end{array}$} & & & & & & \multirow{2}{*}{$\begin{array}{l}\text { "I had all the help and advice } \\
\text { I needed with eating and } \\
\text { nutrition." }\end{array}$} \\
\hline & & Poor & OK & Good & $\begin{array}{l}\text { Very } \\
\text { good }\end{array}$ & Excellent & \\
\hline \multirow{2}{*}{$\begin{array}{l}\text { Being involved in } \\
\text { decisions about your care }\end{array}$} & \multirow{2}{*}{$\begin{array}{l}\text { "No one asked about } \\
\text { what was best for me } \\
\text { and I felt invisible." }\end{array}$} & & & & & & \multirow{2}{*}{$\begin{array}{l}\text { "I was always asked about } \\
\text { what was best for me and I } \\
\text { felt listened to." }\end{array}$} \\
\hline & & Poor & OK & Good & $\begin{array}{l}\text { Very } \\
\text { good }\end{array}$ & Excellent & \\
\hline \multirow{2}{*}{$\begin{array}{l}\text { Organisation and } \\
\text { coordination of care }\end{array}$} & \multirow{2}{*}{$\begin{array}{l}\text { "No one seemed to } \\
\text { know what was } \\
\text { happening. It was totally } \\
\text { disorganised. }\end{array}$} & & & & & & \multirow{2}{*}{$\begin{array}{l}\text { "Everyone knew what was } \\
\text { happening and worked } \\
\text { together well." }\end{array}$} \\
\hline & & Poor & OK & Good & $\begin{array}{l}\text { Very } \\
\text { good }\end{array}$ & Excellent & \\
\hline \multirow{2}{*}{$\begin{array}{l}\text { Information about what } \\
\text { happened in intensive } \\
\text { care }\end{array}$} & \multirow{2}{*}{$\begin{array}{l}\text { "No one told me anything } \\
\text { about how I ended up in } \\
\text { Intensive Care or about } \\
\text { what happened to me." }\end{array}$} & & & & & & \multirow{2}{*}{$\begin{array}{l}\text { "I was given a clear } \\
\text { understanding of how I } \\
\text { ended up in Intensive Care, } \\
\text { and what happened to me." }\end{array}$} \\
\hline & & Poor & OK & Good & $\begin{array}{l}\text { Very } \\
\text { good }\end{array}$ & Excellent & \\
\hline \multirow{2}{*}{$\begin{array}{l}\text { Knowing what to expect } \\
\text { after you got home }\end{array}$} & \multirow{2}{*}{$\begin{array}{l}\text { "No one told me anything } \\
\text { about what being at } \\
\text { home might be like." }\end{array}$} & & & & & & \multirow{2}{*}{$\begin{array}{l}\text { "I was given a clear } \\
\text { understanding of what being } \\
\text { at home might be like." }\end{array}$} \\
\hline & & Poor & OK & Good & $\begin{array}{l}\text { Very } \\
\text { good }\end{array}$ & Excellent & \\
\hline
\end{tabular}

Figure 2 Patient experience questionnaire. 
Table 1 Characteristics of the focus group participants

\begin{tabular}{lll}
\hline Focus groups & Usual care group & Intervention group \\
\hline Numbers and composition & Group 1: 7 participants (4 patients; 3 carers) & Group 1: 6 participants (4 patients; 2 carers) \\
& Group 2: 5 participants (3 patients; 2 carers) & Group 2: 4 participants (3 patients; 1 carer) \\
Patient age & $70(63,78)$ & $55(36,69)$ \\
Proportion male (\%) & 66 & 50 \\
APACHE II score & $23(17,26)$ & $18(15,21)$ \\
Length of ventilation (days) & $11(5,19)$ & $5(4,18)$ \\
ICU length of stay (days) & $12(4,16)$ & $7(5,10)$ \\
Length of hospital stay (days) & $9(6,18)$ & $13(12,80)$ \\
\hline
\end{tabular}

Demographic data were not available for carers. All values represent median (1st, 3rd quartile) unless stated.

ICU, intensive care unit.

tests and median differences (with 95\% CIs). We calculated $\mathrm{p}$ values to assess the significance of any differences between the groups, using $\mathrm{p}<0.05$ as statistically significant. In order to examine the consistency of patient experience between the trial groups, we also explored the variability and dispersion of responses by comparing the IQRs between groups.

\section{Comparative focus groups with patients and family members}

Qualitative approaches can be useful in understanding the clinical context in which complex interventions take place, identifying unexpected causal mechanisms or effects, identifying evolving changes in trial implementation and exploring "what works, for whom, under what circumstances'. ${ }^{20} 33$ Focus group interviews are increasingly used to explore experiences of healthcare. Typically comprising 6-12 participants, they are an efficient means of capturing multiple participants' perspectives. Group dynamics can be particularly helpful in eliciting the views of patients or patient groups who might otherwise be too 'grateful' or reluctant to 'complain', and in identifying potential solutions to shared concerns. ${ }^{34} 35$ We specifically wanted to explore and compare participants' experiences of usual care versus the complex intervention.

We conducted two comparative focus groups with patients and family members in each trial arm $(n=4$ focus groups). The main trial was approved by the Scotland A Research Ethics Committee (10/MRE00/18) and additional written consent was provided by focus group participants. An experienced qualitative researcher (PR) developed topic guides for each trial group, based on pretrial work 242529 and the published taxonomy of intervention $^{26}$ (tables 1 and 2, online supplementary files for indicative topic guides for each group). Participants were given significant freedom to discuss other experiences of care, both positive and negative. The focus groups took place after the primary outcome data (including the PEQ) had been collected after 3 months post-randomisation to minimise bias. Participant characteristics are summarised in table 1.

Focus group discussions were recorded using a digital voice recorder and transcribed verbatim. Data were managed and analysed using qualitative data analysis software (NVIVO V.10). PR developed an a priori analytical framework, based on the four key components of the intervention, which mapped onto the dimensions of the PEQ. We used thematic analysis to collate qualitative data that were relevant to each intervention component, identifying broad patterns of experience therein. ${ }^{36}$ In order to minimise bias, the primary analysis was undertaken by an experienced independent qualitative researcher. A confirmatory analysis was undertaken by PR. All quantitative trial data were unavailable to the qualitative researchers during analysis.

\section{Integration of qualitative and quantitative data}

We adopted a sequential explanatory model to data collection and analysis, ${ }^{37}$ namely the administration and analysis of the quantitative measure (PEQ) across the

Table 2 The four rehabilitation components explored in the study, together with the PEQ domains included in the triangulation with focus group data

\begin{tabular}{ll}
\hline $\begin{array}{l}\text { Aspect of rehabilitation } \\
\text { explored in focus groups }\end{array}$ & Domains of PEQ included \\
\hline Physiotherapy & $\begin{array}{l}\text { Exercises to get you moving/ } \\
\text { back on your feet } \\
\text { Nutritional care }\end{array}$ \\
Help with eating and \\
nutrition \\
Transfer from ICU to the \\
ward \\
Ward staff's understanding \\
of your time in intensive care \\
Help, support and advice \\
with being independent \\
Being involved in decisions \\
about your care \\
Organisation and \\
coordination of care \\
Information about what \\
happened in intensive care \\
Knowing what to expect after \\
you got home
\end{tabular}

ICU, intensive care unit; PEQ, patient experience questionnaire. 
trial population, followed by the conduct and analysis of qualitative focus group interviews, each having equal importance in terms of explanatory power. To integrate data sources, we grouped the nine PEQ dimensions into four areas that represented the key components of the complex intervention (table 2), reporting the median response values, intergroup differences and the dispersion of responses within the PEQ for each group. We then used data from the focus group interviews to help explain our findings and enhance our understanding of patients' experiences of these key components. Illustrative quotes are provided.

\section{RESULTS}

The quantitative responses to the PEQ are summarised in table 3, illustrating the distribution of responses within each trial group, and the differences between the intervention and usual care groups. The integration of the quantitative and qualitative data is presented below according to the four predefined intervention components.

\section{Physiotherapy}

PEQ data indicated general satisfaction across both groups (intervention group median $5.0 \mathrm{vs} 6.1 \mathrm{~cm}$ in the usual care group), but scores were better for intervention group patients $(\mathrm{p}=0.039)$. Intervention group participants gave more consistently satisfied responses (IQR: intervention group 6.8 vs $9.1 \mathrm{~cm}$ in the usual care group). In focus groups, physiotherapy emerged as one of the most important aspects of rehabilitation for all:

Table 3 Summary of quantitative data responses to the nine domains in the patient satisfaction questionnaire administered at 3 months postintervention, when the primary outcome assessment took place

\begin{tabular}{|c|c|c|c|c|c|c|c|c|}
\hline $\begin{array}{l}\text { Intervention } \\
\text { component }\end{array}$ & PEQ domain & $\begin{array}{l}\text { Trial } \\
\text { group }\end{array}$ & Respondents & $\begin{array}{l}\text { Median } \\
\text { score* }^{\star} \\
(\mathrm{cm})\end{array}$ & $\begin{array}{l}\text { 1st, 3rd } \\
\text { quartile } \\
\text { (cm) }\end{array}$ & $\begin{array}{l}\text { Interquartile } \\
\text { distance } \\
\text { (cm) }\end{array}$ & $\begin{array}{l}\text { Median } \\
\text { difference } \\
(95 \% \mathrm{Cl})(\mathrm{cm})\end{array}$ & p Value \\
\hline \multirow[t]{2}{*}{ Physiotherapy } & \multirow{2}{*}{$\begin{array}{l}\text { Exercises to } \\
\text { get you } \\
\text { moving/back } \\
\text { on your feet }\end{array}$} & $U$ & 83 & 6.1 & $1.2,10.3$ & 9.1 & \multirow[t]{2}{*}{$1.40(0.00$ to 4.00$)$} & \multirow[t]{2}{*}{$0.039 \dagger$} \\
\hline & & 1 & 95 & 5.0 & $1.1,7.9$ & 6.8 & & \\
\hline \multirow{2}{*}{$\begin{array}{l}\text { Nutritional } \\
\text { care }\end{array}$} & Help with & $U$ & 87 & 9.9 & $4.8,14.5$ & 9.7 & \multirow[t]{2}{*}{$1.60(0.00$ to 3.80$)$} & \multirow[t]{2}{*}{$0.038 \dagger$} \\
\hline & $\begin{array}{l}\text { eating and } \\
\text { nutrition }\end{array}$ & 1 & 95 & 5.4 & $2.3,10.0$ & 7.7 & & \\
\hline Case & Transfer from & $U$ & 73 & 5.7 & $1.7,14.9$ & 13.2 & \multirow{2}{*}{$0.20(-0.90$ to 2.80$)$} & \multirow[t]{2}{*}{0.481} \\
\hline \multirow[t]{9}{*}{ management } & $\begin{array}{l}\text { ICU to the } \\
\text { ward }\end{array}$ & 1 & 67 & 5.2 & $4.8,10.0$ & 5.2 & & \\
\hline & Ward staff's & $U$ & 78 & 5.1 & $1.1,10.2$ & 9.1 & \multirow[t]{2}{*}{$0.00(-1.10$ to 1.20$)$} & \multirow[t]{2}{*}{0.850} \\
\hline & $\begin{array}{l}\text { understanding } \\
\text { of your time in } \\
\text { intensive care }\end{array}$ & I & 87 & 5.1 & $1.9,8.0$ & 6.1 & & \\
\hline & Help, support & $U$ & 81 & 5.5 & $1.2,10.1$ & 8.9 & \multirow{2}{*}{$0.10(-1.10$ to 1.40$)$} & \multirow[t]{2}{*}{0.787} \\
\hline & $\begin{array}{l}\text { and advice } \\
\text { with being } \\
\text { independent }\end{array}$ & 1 & 95 & 5.3 & $2.6,10.0$ & 7.4 & & \\
\hline & Being involved & $U$ & 81 & 10.0 & $5.0,15.0$ & 10.0 & \multirow[t]{2}{*}{$0.70(-0.40$ to 3.30$)$} & \multirow[t]{2}{*}{0.226} \\
\hline & $\begin{array}{l}\text { in decisions } \\
\text { about your } \\
\text { care }\end{array}$ & 1 & 91 & 7.3 & $4.8,14.3$ & 9.5 & & \\
\hline & Organisation & $U$ & 83 & 7.1 & $4.8,12.0$ & 7.2 & \multirow[t]{2}{*}{$1.30(0.00$ to 3.50$)$} & \multirow[t]{2}{*}{$0.045 \dagger$} \\
\hline & $\begin{array}{l}\text { and } \\
\text { coordination of } \\
\text { care }\end{array}$ & 1 & 96 & 5.3 & $2.2,10.0$ & 7.8 & & \\
\hline Information & Information & $U$ & 68 & 10.2 & $5.0,16.9$ & 11.9 & \multirow[t]{2}{*}{4.90 (2.80 to 8.00$)$} & \multirow[t]{2}{*}{$<0.001 \dagger$} \\
\hline \multirow[t]{3}{*}{ provision } & $\begin{array}{l}\text { about what } \\
\text { happened in } \\
\text { intensive care }\end{array}$ & 1 & 83 & 3.6 & $1.0,10.0$ & 9.0 & & \\
\hline & Knowing what & U & 81 & 10.0 & $5.0,15.0$ & 10.0 & \multirow[t]{2}{*}{$0.50(-0.40$ to 3.30$)$} & \multirow[t]{2}{*}{0.308} \\
\hline & $\begin{array}{l}\text { to expect after } \\
\text { you got home }\end{array}$ & I & 89 & 7.2 & $2.6,14.9$ & 12.3 & & \\
\hline
\end{tabular}


The biggest saviour in the whole thing has probably been the physio... physio is the main thing. (Usual care participant 1)

Experiences of physiotherapy varied widely in the usual care group, however, and participants frequently remarked upon resource constraints (lack of staffing) and its perceived impact upon recovery.

He (husband) wanted out of bed and he wanted to make a recovery, but if you've no(t) got the bodies (staff) there to help.... (Usual care participant's wife 2)

In contrast, intervention participants valued the frequency and consistency of physiotherapy provided by RAs.

I had two (physio) sessions-a morning and an afternoon... (Intervention participant 3)

Intervention participants highly valued the timing and delivery of physiotherapy according to their individual abilities, needs and preferences, facilitating greater involvement in the rehabilitation process.

If there was anything that I felt that I couldn't do, or it was too much, I was just to rest get my breath if need be, and just tell them (RAs) when I was ready...and every time they would say "What would you like to do today?" and in the end I could pick what I wanted. (Intervention participant 4)

Explanation, support and encouragement to perform exercises unsupervised were also highly valued.

If you're left with a sheet of paper to say, do these exercises on a daily basis, I am not likely to be motivated, but if somebody is... physically there, saying "Do these, let's do it together", it's very different. (Intervention participant 3)

Overall, the RAs provided continuity and consistency of care in accordance with intervention group participants' individual needs, abilities and preferences.

\section{Nutritional care}

Responses to the PEQ revealed greater satisfaction in the intervention group (median response 5.4 vs $9.9 \mathrm{~cm}$ in the usual care group $(\mathrm{p}=0.038))$. Intervention participants were also more consistently satisfied (IQR 7.7 vs $9.7 \mathrm{~cm}$ ). In the focus groups, nutritional care was universally perceived as important to recovery, but experiences varied widely among the usual care group.

She (dietitian) checked what I was eating... She said you could do with a wee (little) bit more of such and such, so she arranged to have that wee bowl of fruit or something. (Usual care participant 5)
Several participants, however, felt that nursing staff were too busy to physically help them eat or deliver prescribed supplements.

Nobody was interested. I was actually taking him (husband) in flasks of porridge to try and encourage him to eat...I was actually spoon feeding him...he was so weak, it was like there was nobody there to do this. (Usual care patient's wife 2)

Intervention participants, in contrast, valued the RAs' physical assistance with eating (including nutritional supplements) and support to achieve prescribed nutritional targets, using individualised feedback. Also valued was their advocacy in relaying dietary concerns to relevant ward-based clinicians.

I managed to say, “(RA), I can't manage this (high protein supplement)". Can you speak to (the ward-based Dietitian) about it? And we did work out something and it worked, because I...asked (RA) to represent me, because with (ward-based Dietitian), I couldn't get through. (Intervention participant 6)

One intervention participant particularly valued the RA's support in accompanying her to the hospital canteen.

I was really grateful to (RA). She would spare the time to take me downstairs (to the hospital canteen) and bring me back up during lunch to just try and encourage me to eat. (Intervention participant 6)

Overall, the RAs appeared to more consistently operationalise dietetic recommendations, individualising care according to patients' needs and preferences.

\section{Case management}

Median PEQ responses to the questions 'transfer from ICU to the ward', 'ward staff's understanding of your time in intensive care' and 'help, support and advice with being independent' were similar between the groups with values between 5 and $6 \mathrm{~cm}$ ('very good'). However, for all these domains, the $\mathrm{IQR}$ values were wider for the usual care group, notably for the 'transfer from ICU to the ward' (13.2 vs $5.2 \mathrm{~cm})$, suggesting wider variation in experience. Responses to 'being involved in decisions about your care' were less positive (usual care 10.0 vs $7.3 \mathrm{~cm}$ in the intervention group) with wide variation in responses for both groups. The most direct question about case management, 'organisation and coordination of care', indicated better experience among intervention patients (5.3 vs $7.2 \mathrm{~cm}$; $\mathrm{p}=0.045)$.

In the focus groups, clear differences emerged between the groups. Both described a perceived deterioration in the quality of care following transfer to the general wards, which was attributed to staff shortages, high workload and the dependency of other patients. 
You know the NHS is short staffed, you know that with their resources....but I mean you're giving them all this care in Intensive Care, and after that, it's like you're thrown to the dogs. (Usual care participant's wife 2)

Experiences across both groups were very variable, and seemed dependent on the discharge destination (specific ward). The experience of usual care participants appeared less consistent; several appeared to 'slip through the net', for example, in terms of pre-discharge assessment and provision of aids and adaptations for community living.

Was somebody supposed to come down and assess...her needs? If she needed anything adapted...needed any kind of equipment or stuff like that? That never happened. (Usual care patient's son, 7)

Usual care participants frequently described the 'push' for hospital discharge, a general lack of involvement in decision-making and communication that was often ambiguous, contradictory and 'last minute'.

I think for... basically knocking on Death's door, I think the length of time between coming out of Intensive Care and going home is far, far too short. They are in a rush to...get people out. (Usual care patient's son, 7)

Usual care participants were also critical of a lack of postdischarge follow-up.

I thought we might have been asked to come back for a check-up after so many weeks... I've never heard anything about anything like that. (Usual care patient 8)

Intervention participants, in contrast, valued the RA's assistance across multiple roles, including assistance with eating, washing and dressing, coordination of relevant assessments and referrals, and communication of discharge plans. Intervention group participants attributed this support to consistency and continuity of care.

Having one person assigned to you, I thought that was marvellous, you know? There was always that one person that you knew you would see almost, probably every day....and if you had any worries you could talk to that one person and your worries got to the right source...the source that would do something about it. (Intervention patient 3)

Other examples included the coordination of postdischarge support.

I felt I was very lucky because the day of my discharge, (the RA) had managed to gather all the things I needed, had managed to secure all the telephone numbers that I might need...I didn't have any qualms about going home.... (Intervention participant 6)

\section{Information provision}

Responses to 'information about what happened in intensive care' showed the largest between-group differences, with intervention patients reporting the greatest and usual care patients the lowest satisfaction across all PEQ domains $(10.2$ vs $3.6 \mathrm{~cm}$; $\mathrm{p}<0.001)$. In contrast, group responses were similar to 'knowing what to expect after you got home', with poorer median values than for many domains (intervention group $7.2 \mathrm{vs} 10.0 \mathrm{~cm}$ in the usual care group) and wide variation in satisfaction for both groups. These data suggest that the intervention improved information provision relating to the critical illness episode, but persisting unmet informational need following hospital discharge.

Focus group data strongly supported these findings. Amnesia, strange dreams and delusional memories were prevalent for all patients, and limited recall of the ICU admission and early post-discharge period was frequently described. Usual care participants frequently felt ill-informed about the circumstances and chronology of events surrounding their ICU admission and relied almost exclusively upon family members for information. This contributed to anxiety around potential recurrence, ill-explained critical illness-related morbidity, the protraction and limits of the recovery process and the long-term implications of critical illness. Several usual care participants attributed greater anxiety to acquiring information from independent sources, such as the internet.

I still don't know why I ended up in there (ICU). Well, I know why, but I don't know why I got what I got...I worry a lot more about my health than I ever did before, because I've got no idea what started it. I think that's the biggest problem. I went on the internet and looked up... the septic shock thing and what that entailed...and I wish to God that I hadn't...because I felt like I'd just been knocked back about six steps.... (Usual care participant 8)

When asked, many agreed that a clear outline of "what happened' would have been helpful.

I think it would have helped me...definitely, just to fill in all the blanks. I would like to know what happened with this and what happened with that and...but I never got anything like that. (Usual care participant 9)

In marked contrast, intervention participants valued the structured, individualised information they received. The discussion with an ICU physician was generally valued for the opportunity to 'fill in the blanks', especially reasons for ICU admission and the clinical course. Some focus group participants declined, however, describing their ICU experience as too 'raw' in the early post-ICU period.

I think them coming to see you helps to fill that void, you know, because being in Intensive Care, it's almost like you've lost a number of days without knowing what's happening...(the ICU Consultant) managed to explain the 
facts and...what you went through...why you ended up in Intensive Care. It really did help...me to put things in chronological order. (Intervention participant 10)

The individualised lay summary of the ICU admission was valued for its easily understandable explanation, although the terminology used and its occasional receipt by post (after hospital discharge) sometimes caused anxiety, highlighting the value of face-to-face clarification, reassurance and the opportunity to ask questions.

Mine was good...but I got a wee (little) bit of a fright... although I knew I was on the breathing machine, I didn't know that it was...called a life support machine and see when I seen it written down...! (Intervention participant 11)

When participants accepted the offer of an ICU visit prior to hospital discharge, it was generally valued as an opportunity to make sense of the critical illness episode. However, timing was important, with several focus group participants reporting that their experiences were still 'too raw'. Finally, the therapeutic relationship with the RA appeared to facilitate the sensitive timing and presentation of information in accordance with patients' needs, emotional status and ability to retain information.

\section{DISCUSSION}

This mixed methods process evaluation provides valuable insights into patient/carer experiences in a complex intervention trial of post-ICU acute hospital rehabilitation. There was substantial concordance between cohort-level questionnaire data and the detailed accounts of focus group participants. Evidence of greater satisfaction with physiotherapy, nutritional care, information provision and coordination of care emerged from both data sources, suggesting that a casemanagement approach, delivered by a dedicated RA, improved patient experience of post-ICU acute hospital rehabilitation. Furthermore, focus group data revealed the high value intervention participants placed on the individualisation of their care, according to their needs, abilities and preferences.

Despite evidence of greater satisfaction in the intervention group, we found no statistically or clinically significant between-group differences across functional, physical, psychological and HRQoL outcomes between hospital discharge and 12 months follow-up in the trial. ${ }^{17}$ The discordance between these 'biomedical' outcomes and greater reported patient satisfaction is striking. It is possible that biomedical outcomes are resistant to modification at this stage of recovery, ${ }^{38}$ or that they fail to measure 'what matters' to patients during acute hospital-based recovery. ${ }^{38} 39$ The performance of outcome measures also depends on their appropriate selection, their psychometric properties in the population of interest and the timing of data collection in accordance with the delivery of the intervention.
We note with interest that only one previous study of a post-ICU critical rehabilitation intervention employed qualitative approaches in its evaluation. ${ }^{21}$ The authors demonstrated that intervention participants not only experienced improvements in objective measures of fitness but also an increased sense of motivation, wellbeing, achievement and social participation. In the future, such studies would be well advised to incorporate qualitative approaches and process evaluations into trial design to explore patients' experiences of the intervention (including unanticipated benefits and drawbacks) that may not be accessible by existing questionnaires.

Qualitative studies among other hospitalised patient groups have shown the high value that patients place on the therapeutic or collaborative relationship with rehabilitation staff, flexibility around the timing, content and delivery of rehabilitation and its individualisation according to needs and preferences. ${ }^{40-42}$ These issues underpinned the development of the RECOVER intervention, and the PEQ was specifically developed to capture them. Our data provide strong evidence for important effects on these person-centred outcomes. Our evaluation demonstrates the added value that qualitative research can add in RCTs, particularly in the design and conduct of a trial, improving its internal and external validity, facilitating replicability, interpretation and generalisability of findings ${ }^{43}$ and here, in exploring the value of individual components of a complex intervention.

A key finding was the value participants placed on information. The 'need to know' has long been reported in the critical care literature, ${ }^{44}$ underpinning various strategies such as ICU discharge summaries, ${ }^{45}$ patient diaries, ${ }^{46-48}$ follow-up clinics ${ }^{49} 50$ and return visits to the ICU. ${ }^{51}$ Our comprehensive, individualised approach was documentary (rehabilitation manual; individualised lay summary), didactic (discussion with ICU physician and the RAs) and experiential (offer of a return visit to the ICU). Qualitative and quantitative data provided strong evidence for the benefit of information, and focus group data uncovered preferences for its timing, content (including terminology) and delivery. These findings support the need for individualised information in routine post-ICU care.

A particular strength of our process evaluation was consideration of the clinical context in which the intervention took place, and participants' response to and interaction with the intervention. These are recommended when evaluating how or why complex healthcare interventions may (or may not) work. ${ }^{20}$ Our data provide empirical evidence that enhanced access to physiotherapy, nutritional care and information is important to patients during recovery, but highlight a range of preferences and the need for individualised content, delivery and timing. Case management by a dedicated RA was a key 'active ingredient' that facilitated these preferences and seemed to increase engagement in the rehabilitation process, resulting in greater overall 
perceived benefit. A potential limitation of our findings is the marked differences between the focus group's patient participants in terms of patient age, duration of mechanical ventilation and ICU length of stay.

Our findings are relevant to future trial design in this patient population. Specifically, trial interventions that use individual adaptation versus standardised or fixed interventions require different approaches to process and effectiveness evaluation. ${ }^{52} 53$ We standardised the process and function of the intervention (ie, individualisation and patient engagement in the rehabilitation process, respectively) but not the content, capturing actual differences in treatments received in the process evaluation. This approach is particularly recommended when the 'real world' or clinical context is complex. ${ }^{20}$ With this perspective, the internal validity of a trial should be defined functionally as well as compositionally. ${ }^{33} 52$ Our data indicate that concordance between biomedical and person-centred outcomes should not be assumed ${ }^{37}$ highlighting the importance of specific standardised measures (few currently exist) and the use of qualitative approaches to capture the latter.

Importantly, cost-effectiveness analysis of the RECOVER trial found no incremental cost-effectiveness over the 12 months post-randomisation, and no difference in quality-adjusted life years between the groups. ${ }^{17}$ It is increasingly recognised that HRQoL trajectories are difficult to modify following critical illness, in part because pre-existing comorbidity dominates reported HRQoL during recovery. ${ }^{54-57}$ Quality of care, patient satisfaction and 'person-centeredness' are excluded from cost-effectiveness analysis. The use of service models based on multiskilled RAs providing individualised case management is potentially cost-neutral or even costsaving compared to existing models that require multiple specialists from different disciplines. Our data provide strong evidence that this approach delivers higher quality care from patients' and carers' perspectives and may well justify service redesign. Our model of care has been adopted into routine clinical practice at the main study hospital.

In conclusion, we have shown that physiotherapy, nutritional care and information are highly valued by patients during post-ICU acute hospital rehabilitation. A rehabilitation strategy coordinated by a dedicated multiskilled RA improved patients' satisfaction with and perceived quality of care, cutting across traditional disciplinary boundaries, ward-level resource constraints and circumventing communication failures. The focus on individualised, coordinated care according to patient ability and preference was highly valued.

Twitter Follow David Griffith at @Griffith_DM

Acknowledgements The authors acknowledge Professor Andrew Thompson (University of Edinburgh, Scotland) for his expert advice on the development of the patient experience questionnaire used in this trial.

Collaborators RECOVER collaborators include: Julia A Boyd, Simon J Mackenzie, Ashma Krishan, Stephanie C Lewis, Gordon D Murray, John F
Forbes, Joel Smith, Alastair M Hull, Charles Wallis, Joyce Stewart, Anthony Bateman, Elizabeth Wilson, Mike Gillies, Susanne Kean, David Hope, Heidi Dawson, Corrienne McCulloch, Jean Antonelli, Louise Boardman and rehabilitation assistants Leanne Dow, Winchell Williams, Audrey McCann and Sarah Alexander.

Contributors TW, LS, PR, JM and GH designed the trial and completed pilot and feasibility work. Specialist clinical input to trial conduct was provided by TW and DG (critical care perspective), LS (physiotherapy/rehabilitation), PR and JR (nursing) and JM (dietetics). Statistical advice was provided by Professor Gordon D Murray and Professor Stephanie C Lewis (both at the University of Edinburgh). The patient experience questionnaire was developed by PR, with expert methodological advice provided by Professor Andrew Thompson at the University of Edinburgh. The qualitative focus group interviews were designed by PR and GH and conducted and analysed by PR. All coauthors contributed to the mixed methods integration and analysis.

Funding The trial was funded by the Chief Scientist Office, Scotland (grant number $\mathrm{CZH} / 4 / 53$ ).

Competing interests None declared.

Ethics approval Scotland A Research Ethics Committee.

Provenance and peer review Not commissioned; externally peer reviewed.

Data sharing statement Additional unpublished data may be requested by contacting the lead author.

Open Access This is an Open Access article distributed in accordance with the Creative Commons Attribution Non Commercial (CC BY-NC 4.0) license, which permits others to distribute, remix, adapt, build upon this work noncommercially, and license their derivative works on different terms, provided the original work is properly cited and the use is non-commercial. See: http:// creativecommons.org/licenses/by-nc/4.0/

\section{REFERENCES}

1. Needham DM, Davidson J, Cohen $\mathrm{H}$, et al. Improving long-term outcomes after discharge from intensive care unit: report from a stakeholders' conference. Crit Care Med 2012;40:502-9.

2. Centre for Clinical Practice at NICE. National Institute for Health and Clinical Excellence: guidance. Rehabilitation after critical illness. London: National Institute for Health and Clinical Excellence (UK) National Institute for Health and Clinical Excellence, 2009.

3. Bailey P, Thomsen GE, Spuhler VJ, et al. Early activity is feasible and safe in respiratory failure patients. Crit Care Med 2007;35:139-45.

4. Burtin C, Clerckx B, Robbeets C, et al. Early exercise in critically ill patients enhances short-term functional recovery. Crit Care Med 2009;37:2499-505.

5. Schweickert WD, Pohlman MC, Pohlman AS, et al. Early physical and occupational therapy in mechanically ventilated, critically ill patients: a randomised controlled trial. Lancet 2009;373:1874-82.

6. Denehy L, Skinner EH, Edbrooke L, et al. Exercise rehabilitation for patients with critical illness: a randomized controlled trial with 12 months of follow-up. Crit Care 2013;17:R156.

7. Moss M, Nordon-Craft A, Malone D, et al. A randomized trial of an intensive physical therapy program for acute respiratory failure patients. Am J Respir Crit Care Med 2016;193:1101-10.

8. Hopkins RO, Miller RR III, Rodriguez L, et al. Physical therapy on the wards after early physical activity and mobility in the intensive care unit. Phys Ther 2012;92:1518-23.

9. McWilliams DJ, Atkinson D, Carter A, et al. Feasibility and impact of a structured, exercise-based rehabilitation programme for intensive care survivors. Physiother Theory Pract 2009;25:566-71.

10. Elliott D, McKinley S, Alison J, et al. Health-related quality of life and physical recovery after a critical illness: a multi-centre randomised controlled trial of a home-based physical rehabilitation program. Crit Care 2011;15:R142.

11. Jackson JC, Ely EW, Morey MC, et al. Cognitive and physical rehabilitation of intensive care unit survivors: results of the RETURN randomized controlled pilot investigation. Crit Care Med 2012;40:1088-97.

12. Batterham AM, Bonner S, Wright J, et al. Effect of supervised aerobic exercise rehabilitation on physical fitness and quality-of-life in survivors of critical illness: an exploratory minimized controlled trial (PIX study). Br J Anaesth 2014;113:130-7. 
13. Kayambu G, Boots R, Paratz J. Physical therapy for the critically il in the ICU: a systematic review and meta-analysis. Crit Care Med 2013;41:1543-54

14. Calvo-Ayala E, Khan BA, Farber MO, et al. Interventions to improve the physical function of ICU survivors: a systematic review. Chest 2013;144:1469-80.

15. Li Z, Peng X, Zhu B, et al. Active mobilization for mechanically ventilated patients: a systematic review. Arch Phys Med Rehabil 2013;94:551-61.

16. Stiller K. Physiotherapy in intensive care: an updated systematic review. Chest 2013;144:825-47.

17. Walsh TS, Salisbury LG, Merriweather JL, et al. Increased hospital-based physical rehabilitation and information provision after intensive care unit discharge: the RECOVER randomized clinical trial. JAMA Intern Med 2015;175:901-10.

18. Mehlhorn J, Freytag A, Schmidt K, et al. Rehabilitation interventions for postintensive care syndrome: a systematic review. Crit Care Med 2014;42:1263-71.

19. Craig P, Dieppe P, Macintyre S, et al. Developing and evaluating complex interventions: the new Medical Research Council guidance. BMJ 2008;337:a1655.

20. Moore GF, Audrey S, Barker M, et al. Process evaluation of complex interventions: Medical Research Council guidance. BMJ 2015;350: h1258

21. Walker W, Wright J, Danjoux G, et al. Project Post Intensive Care eXercise (PIX): a qualitative exploration of intensive care unit survivors' perceptions of quality of life post-discharge and experience of exercise rehabilitation. J Intensive Care Soc 2014:16:37-44

22. Collen FM, Wade DT, Robb GF, et al. The Rivermead Mobility Index: a further development of the Rivermead Motor Assessment. Int Disabil Stud 1991;13:50-4.

23. Podsiadlo D, Richardson S. The timed "Up \& Go": a test of basic functional mobility for frail elderly persons. J Am Geriatr Soc 1991;39:142-8

24. Jenkinson $C$, Layte $R$, Jenkinson $D$, et al. A shorter form health survey: can the SF-12 replicate results from the SF-36 in longitudinal studies? J Public Health Med 1997;19:179-86.

25. Zigmond AS, Snaith RP. The hospital anxiety and depression scale. Acta Psychiatr Scand 1983;67:361-70.

26. Davidson JR, Book SW, Colket JT, et al. Assessment of a new self-rating scale for post-traumatic stress disorder. Psychol Med 1997;27:153-60.

27. Salisbury LG, Merriweather JL, Walsh TS. Rehabilitation after critical illness: could a ward-based generic rehabilitation assistant promote recovery? Nurs Crit Care 2010;15:57-65.

28. Salisbury LG, Merriweather JL, Walsh TS. The development and feasibility of a ward-based physiotherapy and nutritional rehabilitation package for people experiencing critical illness. Clin Rehabil 2010;24:489-500.

29. Ramsay $P$, Salisbury LG, Merriweather JL, et al. A rehabilitation intervention to promote physical recovery following intensive care: a detailed description of construct development, rationale and content together with proposed taxonomy to capture processes in a randomised controlled trial. Trials 2014;15:38.

30. Walsh TS, Salisbury LG, Boyd J, et al. A randomised controlled trial evaluating a rehabilitation complex intervention for patients following intensive care discharge: the RECOVER study. BMJ Open 2012;2: e001475.

31. Ramsay P. Quality of life following prolonged critical illness: a mixed methods study. University of Edinburgh, 2010.

32. Coyle J, Williams B. An exploration of the epistemological intricacies of using qualitative data to develop a quantitative measure of user views of health care. J Adv Nurs 2000;31:1235-43.

33. Bonell C, Fletcher A, Morton M, et al. Realist randomised controlled trials: a new approach to evaluating complex public health interventions. Soc Sci Med 2012;75:2299-306.

34. Onwuegbuzie AJ, Dickinson WB, Leech NL, et al. Toward more rigor in focus group research in stress and coping and beyond a new mixed research framework for collecting and analyzing focus group data, 2010.
35. Kitzinger J. Qualitative research: introducing focus groups. BMJ 1995;311:299-302.

36. Braun V, Clarke V. Using thematic analysis in psychology. Qual Res Psychol 2006;3:77-101.

37. Creswell JW, Plano Clark VL, Gutmann ML, et al. Advanced mixed methods research designs. In: Tashakkori A, Teddlie C, eds. Handbook of mixed methods in social and behavioral research. Thousand Oaks (CA): Sage, 2003:209-40.

38. Cox CE, Hough CL. Improving functional recovery after critical illness. JAMA Intern Med 2015;175:911-12.

39. Ramsay P. Health-related quality of life: implications for critical care interventional studies and why we need to collaborate with patients. Curr Opin Crit Care 2011;17:510-14.

40. Whalley Hammell K. Experience of rehabilitation following spinal cord injury: a meta-synthesis of qualitative findings. Spinal Cord 2007;45:260-74.

41. Lindberg J, Kreuter M, Taft C, et al. Patient participation in care and rehabilitation from the perspective of patients with spinal cord injury. Spinal Cord 2013;51:834-7.

42. Peoples H, Satink T, Steultjens E. Stroke survivors' experiences of rehabilitation: a systematic review of qualitative studies. Scand J Occup Ther 2011;18:163-71.

43. O'Cathain A, Thomas K, Drabble S, et al. What can qualitative research do for randomised controlled trials? A systematic mapping review. BMJ Open 2013;3:e002889.

44. Hupcey JE, Zimmerman HE. The need to know: experiences of critically ill patients. Am J Crit Care 2000;9:192-8.

45. Bench S, Day T. The user experience of critical care discharge: a meta-synthesis of qualitative research. Int J Nurs Stud 2010;47:487-99.

46. Jones C, Backman C, Capuzzo M, et al. Intensive care diaries reduce new onset post traumatic stress disorder following critical illness: a randomised, controlled trial. Crit Care 2010;14: R168.

47. Egerod I, Christensen D, Schwartz-Nielsen KH, et al. Constructing the illness narrative: a grounded theory exploring patients' and relatives' use of intensive care diaries. Crit Care Med 2011;39:1922-8.

48. Ewens BA, Hendricks JM, Sundin D. The use, prevalence and potential benefits of a diary as a therapeutic intervention/tool to aid recovery following critical illness in intensive care: a literature review. $J$ Clin Nurs 2015;24:1406-25.

49. Storli SL, Lind R. The meaning of follow-up in intensive care: patients' perspective. Scand J Caring Sci 2009;23:45-56.

50. Crocker C. A multidisciplinary follow-up clinic after patients discharge from ITU. Br J Nurs 2003;12:910-14.

51. Engstrom A, Andersson S, Soderberg S. Re-visiting the ICU experiences of follow-up visits to an ICU after discharge: a qualitative study. Intensive Crit Care Nurs 2008;24: 233-41.

52. Hawe P, Shiell A, Riley T. Complex interventions: how "out of control" can a randomised controlled trial be? BMJ 2004;328:1561-3

53. Bird L, Arthur A, Cox K. "Did the trial kill the intervention?" Experiences from the development, implementation and evaluation of a complex intervention. BMC Med Res Methodol 2011;11:24.

54. Bagshaw SM, Stelfox HT, Johnson JA, et al. Long-term association between frailty and health-related quality of life among survivors of critical illness: a prospective multicenter cohort study. Crit Care Med 2015;43:973-82.

55. Orwelius L, Nordlund A, Nordlund $P$, et al. Pre-existing disease: the most important factor for health related quality of life long-term after critical illness: a prospective, longitudinal, multicentre trial. Crit Care 2010;14:R67.

56. Lone NI. Evaluation of five year survival and major health care resource use following admission to Scottish intensive care units. University of Edinburgh, 2013.

57. Iwashyna TJ. Trajectories of recovery and dysfunction after acute illness, with implications for clinical trial design. Am J Respir Crit Care Med 2012;186:302-4. 